\title{
Psychological Needs as Mediators of Income-Life Satisfaction Relationship in Croatian Adults
}

\author{
Ana Butković \\ ORCID: 0000-0002-8709-8092 • ResearcherID: T-8202-2017 \\ Tena Vukasović Hlupić \\ ORCID: 0000-0003-3734-5582 • ResearcherID: T-8208-2017 \\ Denis Bratko \\ ORCID: 00oo-0002-2482-4413• ResearcherID: T-8213-2017 \\ University of Zagreb, Faculty of Humanities and Social Sciences
}

Received 21 September $2017 \cdot$ Revised 30 October 2017 Accepted 17 November 2017

Abstract

\begin{abstract}
Aim of this study was to examine the relationship between relative income, psychological needs satisfaction and life satisfaction in a sample of Croatian adults. Participants assessed their household income relative to Croatian average income, life satisfaction with Satisfaction with Life Scale, and level of basic psychological needs satisfaction with Basic Psychological Needs Scale. The total sample included 397 participants $(54.9 \%$ female, mean age 31.23 years, $S D=8.71)$. We identified two groups based on relative income, one with average income and the other with higher than average income. Belonging to group with higher income was associated with higher needs and life satisfaction, with two satisfactions positively associated. Therefore, we tested if psychological needs satisfaction mediated income-life satisfaction relationship. Results from parallel multiple mediator model showed that satisfaction of all three psychological needs mediated the relationship between income and life satisfaction, but income also had a direct effect on life satisfaction.
\end{abstract}

Keywords: income, life satisfaction, psychological needs satisfaction, mediation.

\section{Introduction}

Would you be happier if you were rich(er)? Ever since Easterlin (1974) stated that happiness at a national level does not increase with wealth once basic needs are fulfilled, which has become known as Easterlin paradox, studies have examined the relationship between income and well-being. Different hypotheses about the relationship between income and individual's wellbeing have been proposed. On one hand, absolute income is considered the best measure of individual's well-being because greater income enables advantages such as higher consumption, more choices, and fewer constraints for survival. On the other hand, relative income, namely comparison with income standard or with social reference group, is important for individual's well-being because people like having more than other people. Finally, some authors believe that

(C) Authors. Terms and conditions of Creative Commons Attribution 4.0 International (CC BY 4.0) apply. Correspondence: Ana Butković, Faculty of Humanities and Social Sciences, Ivana Lučića 3, 10000 Zagreb, HR. E-mail: abutkovi@ffzg.hr. Tel: +38514092194. 
rank income matters most, or individual's ranked position within a comparison group (Boyce, Brown \& Moore, 2010). In their study Boyce et al. (2010) analyzed seven years of the British Household Panel Survey (BHPS) and compared absolute and rank income as predictors of life satisfaction. Independently both income variables significantly predicted life satisfaction, but when entered together only rank income was a significant predictor.

The relationship between income and well-being seems to differ not only when different types of income are taken into account, but also when different aspects of well-being are taken into account. Subjective well-being consists of cognitive aspect or general life satisfaction evaluation, and affective aspect or the relative ratio of positive and negative emotions in one's life. In a study analyzing more than 450 ooo US responses to the Gallup-Healthways Well-Being Index, affective and cognitive aspects of well-being had different relationships with income (Kahneman \& Deaton, 2010). While life evaluation increased steadily with increasing income, measures of emotional well-being increased only to a point of $\sim \$ 75$ ooo annual income with no further improvement. This finding means that as people become rich(er), they tend to evaluate their life as more satisfying. On the other hand, as people become richer than $\sim \$ 75$ ooo annual income, they do not feel more positive about their life. In an analysis including subset of data from the 2005 to 2011 Gallup World Poll (GWP) administered to 806,526 individuals from 135 nations, which had at least three waves of data collection, relationship between household income and subjective well-being was examined. Results showed that income positively influenced life evaluations or cognitive aspect of subjective well-being, but had weaker effects on feelings or affective aspect of subjective well-being (Diener, Tay \& Oishi, 2013). Howell and Howell (2008) examined in their meta-analysis findings of 111 independent samples from 54 economically developing countries. They found that the relationship of economic status and subjective wellbeing differed depending on both how economic status and subjective well-being were operationalized. Their relationship was strongest when economic status was defined as wealth, a stock variable, and not as income, a flow variable, and when subjective well-being was measured as life satisfaction and not as happiness.

Another important aspect of the relationship between income and well-being, included in Easterlin paradox, relates to satisfaction of needs. In line with previously cited studies, analysis of GWP data from 2005 to 2006 including 132 nations showed that both absolute and relative income correlated more with life evaluation than with feelings. This study also included measures of basic psychological needs fulfillment such as respect, relationships, learning new things, managing your time and competence. Results showed that these constructs both significantly correlated with life evaluations and feelings, as well as predicted them (Diener, Ng, Harter \& Arora, 2010). This finding is in line with Ryff's (1989) and Ryan and Deci's (2000) theoretical models that suggest there are basic and universal human psychological needs and that their satisfaction is important for our well-being. According to the Self-determination Theory (SDT; Deci \& Ryan, 1985; Ryan \& Deci, 2000), there are three basic psychological needs. Autonomy refers to the need for performing activities in which individuals feel contentment and are motivated internally as a result of having personal choice. When the need for autonomy is satisfied, people feel the experience of being the initiator of their own behavior and consequently the feelings of choice and psychological freedom. Competence is a need for effective interaction with environment where one has a feeling of control and is encouraged to express his or her capacities. When the need for competence is satisfied, people experience success at challenging tasks and consequently feel internal satisfaction in attaining desired outcomes. Finally, relatedness implies need for establishment of close emotional relations with significant others and important groups of others. When the need for relatedness is satisfied, people feel a sense of communion with others which is accompanied by the experience of reciprocal care and concern for important others. 
Number of studies have shown that psychological needs satisfaction is crucial for happiness and well-being (e.g. Baard, Deci \& Ryan, 2004; Tay \& Diener, 2011; Véronneau, Koestner \& Abela, 2005). When social contexts allow satisfaction of these psychological needs, people thrive, while thwarted satisfaction of needs leads to ill being (Vansteenkiste, Ryan \& Deci, 2008). Economic factors and macroeconomic systems can differently contribute or allow satisfaction of needs for autonomy, competence and relatedness.

A study looking at economic standing, life satisfaction, financial security and psychological need satisfaction among 1,074 non-student adults living in United States, Canada and United Kingdom has shown that the relationship between having money and being satisfied with life is mediated by financial security, a safety need of Maslow's hierarchy, and psychological needs of autonomy, competence, and relatedness composite score (Howell, Kurai \& Tam, 2013). Having money can therefore contribute to our life satisfaction through buying material goods or material purchases and through investing in life experiences or experiential purchases (Van Boven \& Gilovich, 2003). Experiential purchases can contribute to psychological needs satisfaction because when we have more money, we can choose more freely what we want to do with our time thus satisfying the need for autonomy; we can invest more in our abilities satisfying the need for competence; and having different experiences can be a good source of conversation which can increase satisfaction of need for relatedness. In line with that, a recent study asked participants to write how their future would look like if they had the unconditional basic income, a sum given monthly to every adult without further requirements. The coding scheme revealed that the existence of a hypothetical basic income was most often linked to the fulfilment of the basic psychological needs and a positive quality of life. Author concluded that the basic income first and foremost promoted autonomy, which, in turn, had positive interrelations with the other two interconnected basic needs (Giebel, 2017).

The relationship between income and well-being was also examined in several studies in Croatia. Kaliterna Lipovčan, Brkljačić and Šakić (2007) conducted a study on a nationally representative sample of 896 Croatian citizens. They collected data on cognitive and affective components of subjective well-being, as well as satisfaction with specific domains, and their absolute monthly income per household member. Results indicated significantly higher happiness, life satisfaction and satisfaction with several life domains in people with higher absolute monthly income. However, there was no difference between two groups with the highest income. Raboteg-Šarić, Brajša-Žganec and Šakić (2009) collected data on life satisfaction and family economic status as compared to others (i.e. relative income) on 2,832 Croatian adolescents. There were three groups of family economic status: low, average and high. These groups differed in their life satisfaction, with life satisfaction increasing with the increase in relative income. Bratko and Sabol (2006) also found that basic psychological needs satisfaction explained 28\% of variance in life satisfaction on an adult sample aged between 21 and 35 years. However, no study so far has examined the relationship between income, psychological needs satisfaction and life satisfaction in Croatia, especially in a period of recession.

Aim of this study was to examine the relationship between relative income, psychological needs satisfaction and life satisfaction in a sample of Croatian adults. Specifically, we wanted to test if psychological needs satisfaction mediated the relationship between income and life satisfaction, relationship that we hypothesized to be positive. We further hypothesized that psychological needs satisfaction would mediate that relationship in a way that higher income would contribute to higher life satisfaction not only in a direct way, but also through enabling needs satisfaction. 
2. Materials and methods

2.1 Participants and procedure

This study was conducted in Croatia and was a part of a larger research project that included additional variables. The total sample included 397 participants $(54.9 \%$ female, mean age 31.23 years, $S D=8.71$, age range 22-47 years). Data was collected in a group setting on 209 university students (54.1\% female, age range 22-37 years) from different faculty programs and academic profiles (i.e. social, humanistic and technical science), and individually for additional 188 non-student adults (55.9\% female, age range 26-47 years).

\subsection{Measures}

\section{Income}

Participants assessed their household income relative to Croatian average income on a 5-point scale: with ' 1 ' meaning income significantly lower than Croatian average, '2' income somewhat lower, ' 3 ' average income, '4' income somewhat higher, and ' 5 ' income significantly higher than Croatian average. Due to small number of participants endorsing values ' 1 ' and ' 2 ' we grouped participants into two groups, one with predominantly average income (69\%) and the other with higher than average income (31\%).

\section{Life satisfaction}

Life satisfaction was assessed with Satisfaction with Life Scale (SWLS; Pavot \& Diener, 1993) which is meant to assess a cognitive and global evaluation of the quality of one's life as a whole (Pavot \& Diener, 2008). It is a one-factor measure containing five items. Participants gave their answers on a 7-point Likert-type scale ranging from 1 (strongly disagree) to 7 (strongly agree). Cronbach's a reliability in this study was .76 , which is in line with previous studies (e.g. Bratko \& Sabol, 2006; Karaoylas, 2010).

\section{Psychological needs satisfaction}

To measure participant's level of basic psychological need satisfaction, we used Basic Psychological Needs Scale (BPNS; Ryan \& Deci, 2000). The scale consists of 21 items measuring three factors: autonomy ( 7 items), competence ( 6 items) and relatedness ( 8 items). Participants gave their answers on a 7-point Likert-type scale ranging from 1 (strongly disagree) to 7 (strongly agree). Cronbach's a reliability in this study was $.74, .69$, and .71 for autonomy, competence and relatedness, respectively. Reliability coefficients are consistent with previous studies (e.g. Gagné, 2003; Bratko \& Sabol, 2006) as well.

\section{Results}

Results are organized in a way that we first show descriptive results and correlations, then prediction of life satisfaction based on income and psychological needs, and finally the results from the parallel multiple mediator model. 
Table 1. Descriptive results and correlations between variables $(N=397)$

\begin{tabular}{|l|c|c|c|c|c|c|c|c|}
\hline & $\alpha$ & $M$ & $S D$ & $(1)$ & (2) & (3) & (4) \\
\hline (1) Income & - & 1.31 & 0.46 & 1.00 & & & \\
\hline (2) Life satisfaction & .76 & 23.62 & 5.17 & .27 & 1.00 & & \\
\hline (3) Autonomy & .71 & 34.56 & 6.41 & .21 & .52 & 1.00 & \\
\hline (4) Competence & .69 & 29.89 & 5.47 & .23 & .54 & .54 & 1.00 \\
\hline (5) Relatedness & .74 & 44.55 & 6.03 & .13 & .45 & .55 & .44 \\
\hline \multicolumn{7}{c}{ Note. All correlations are significant at $p<.01}$.
\end{tabular}

Descriptive results and correlations between variables are presented in Table 1. As can be seen from the results, all variables were significantly correlated. Psychological needs satisfaction was positively associated with higher life satisfaction $(r=.52, p<.001$ for autonomy; $r=.54, p<.001$ for competence; $r=.45, p<.001$ for relatedness). Also, belonging to a group with higher income was associated both with higher psychological needs satisfaction $(r=.21, p<.001$ for autonomy; $r=.23, p<.001$ for competence; $r=.13, p=.009$ for relatedness) and higher life satisfaction $(r=.27, p<.001)$. This means that, according to Baron and Kenny (1986), all necessary conditions for testing the mediation were met. We first tested mediation hypothesis using regression analysis. Results of regression analyses for each psychological need are presented in Table 2.

Table 2. Results of regression analyses predicting life satisfaction and testing mediation hypothesis $(N=397)$

\begin{tabular}{|c|c|c|c|c|c|c|c|c|c|c|}
\hline & & \multicolumn{3}{|c|}{ Need for autonomy } & \multicolumn{3}{|c|}{ Need for competence } & \multicolumn{3}{|c|}{ Need for relatedness } \\
\hline & 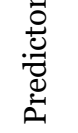 & $\beta$ & $t$ & $\begin{array}{c}\text { Model } \\
\text { summary }\end{array}$ & $\beta$ & $t$ & $\begin{array}{c}\text { Model } \\
\text { summary }\end{array}$ & $\beta$ & $t$ & $\begin{array}{c}\text { Model } \\
\text { summary }\end{array}$ \\
\hline $\begin{array}{l}\overrightarrow{1} \\
\text { चे } \\
\text { th }\end{array}$ & $\begin{array}{l}\Xi \\
\Xi \\
\Xi\end{array}$ & .27 & 5.63 & $\begin{array}{c}\text { Adjusted } R^{2}= \\
.07 \\
F(1,393)=31.68\end{array}$ & .27 & 5.63 & $\begin{array}{c}\text { Adjusted } R^{2}= \\
.07 \\
F(1,393)=31.68\end{array}$ & .27 & 5.63 & $\begin{array}{c}\text { Adjusted } \\
R^{2}=.07 \\
F(1,393)= \\
31.68\end{array}$ \\
\hline $\begin{array}{l}N \\
\text { iे } \\
\text { के }\end{array}$ & 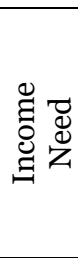 & $\begin{array}{l}.17 \\
.49\end{array}$ & $\begin{array}{l}3.93 \\
11.19\end{array}$ & $\begin{array}{c}\text { Adjusted } R^{2}= \\
.29 \\
F(2,392)= \\
83.50 \\
\Delta R^{2}=.22 \\
F(1,392)= \\
125.30\end{array}$ & $\begin{array}{l}.16 \\
.50\end{array}$ & $\begin{array}{c}3.62 \\
11.68\end{array}$ & $\begin{array}{c}\text { Adjusted } R^{2}= \\
.31 \\
F(2,392)= \\
89.56 \\
\Delta R^{2}=.24 \\
F(1,392)= \\
136.51\end{array}$ & $\begin{array}{l}.22 \\
.42\end{array}$ & $\begin{array}{l}4.94 \\
9.60\end{array}$ & $\begin{array}{c}\text { Adjusted } \\
R^{2}=.25 \\
F(2,392)= \\
65.61 \\
\Delta R^{2}=.18 \\
F(1,392)= \\
92.19\end{array}$ \\
\hline
\end{tabular}

Note. All standardized beta coefficients and values of $F$ test are significant at $p<.001$.

As can be seen from Table 2, inclusion of each psychological need into regression equation resulted in the drop of the standardized beta coefficient value for income, but income still remained a significant predictor of life satisfaction after including each psychological need. This indicated that there is a partial mediation of the income-life satisfaction relationship through psychological needs. However, as can be seen from Table 1, three psychological needs are intercorrelated, with correlations ranging from .44 to .55, so, in our opinion, it made sense to include all three needs in a mediation model simultaneously. Therefore, further step was to test the parallel multiple mediator model (Figure 1). 


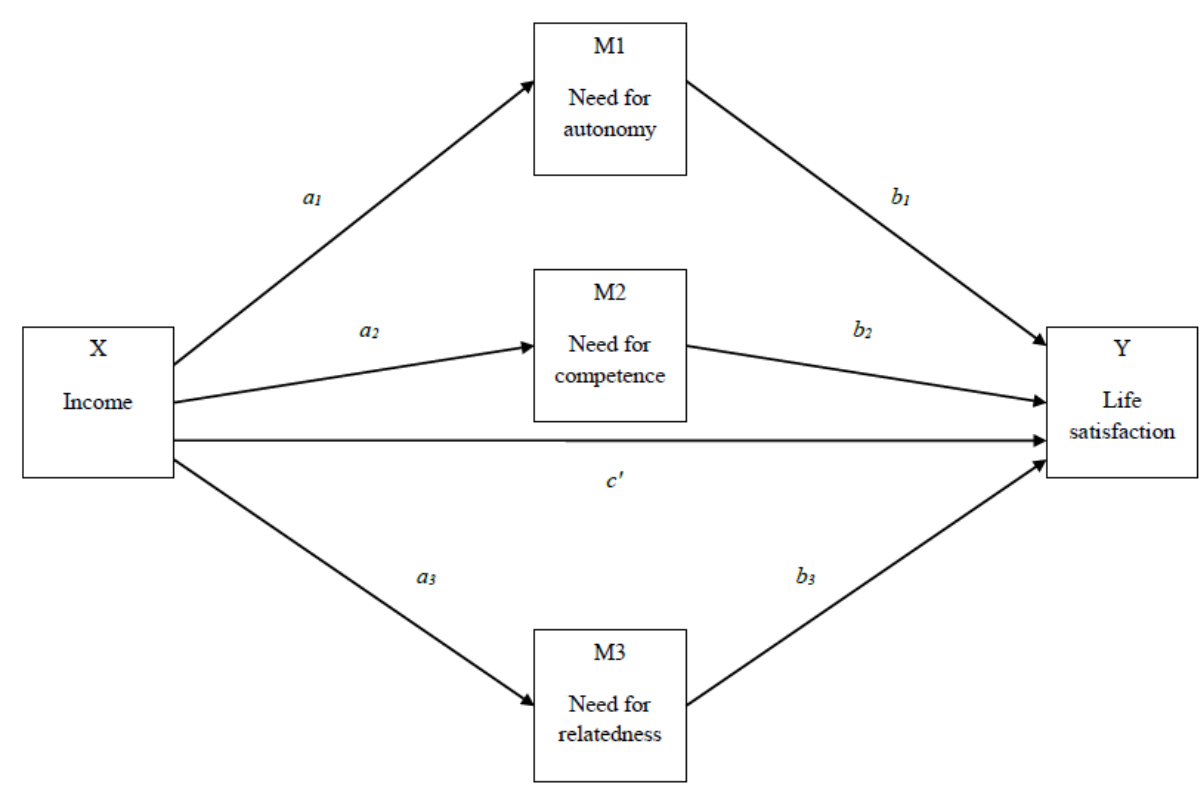

Figure 1. Diagram representing tested parallel multiple mediator model

Using PROCESS macro (Hayes, 2013) we ran multiple mediator analysis where need for autonomy, relatedness and competence were simultaneously entered as mediators of the relationship between income and life satisfaction. Total model explained 40\% of life satisfaction variance. Since our predictor variable, income, was a dichotomous variable coded by a single unit difference, total effect of the model $(c=3.04, p<.001)$ was the difference between the group means on life satisfaction $\left(M_{1}=22.63, S D_{1}=5.11 ; M_{2}=25.67, S D_{2}=4.65\right)$. This difference was statistically significant $(F(1,393)=31.68, p<.001)$ with the higher than average income group having higher life satisfaction than the average income group. This total effect could be partitioned into direct effect of income on life satisfaction $\left(c^{\prime}=1.44, p=.002\right)$ and indirect effects through three needs. We conducted a bias-corrected bootstrap confidence interval based on 10 ooo bootstrap samples for the indirect effect of needs. Confidence intervals for the indirect effect of need for autonomy $\left(a_{1} b_{1}\right) 0.55$ [0.25, 1.00], need for competence $\left(a_{2} b_{2}\right)$ o.80 [0.44, 1.29], and need for relatedness $\left(a_{3} b_{3}\right) 0.25$ [0.06, 0.57] did not include zero, indicating that all three needs were significant mediators. We also performed contrast analysis, to test if specific indirect effects of each need were different. The results indicated that only the effect of need for competence (0.80) was significantly higher than the effect of need for relatedness (0.25), while other effects were not significantly different.

\section{Discussion}

We examined the relationship between relative income, psychological needs satisfaction and life satisfaction in a sample of Croatian adults in time of recession. Average life satisfaction in this sample $(M=23.62, S D=5.17)$ was within the average range $(20-24)$ in economically developed nations (Diener, 2006). We identified two groups of adults based on their relative income, one with average income and one with higher than average income. Higher than average income group had significantly higher life satisfaction compared to average income group. In line with this finding, belonging to a group with higher income was associated with higher life satisfaction. Aim of this study was to test if psychological needs satisfaction mediated this relationship. 
Howell et al. (2013) showed that financial security and psychological need satisfaction, defined as the mean of all items measuring satisfaction of three needs, fully mediated the relationship between economic standing and life satisfaction in a sample of non-student adults from USA, Canada and UK. In our study, we wanted to replicate the finding that psychological needs satisfaction mediates the relationship between economic standing and life satisfaction in a sample from a different culture. We also wanted to test the effect of each need separately. Our results were in line with Howell et al. (2013) study because satisfaction of all three psychological needs mediated the relationship between income and life satisfaction. However, in Howell et al. (2013) financial security reduced the direct effect between economic standing and life satisfaction by $66 \%$ while psychological need satisfaction reduced the direct effect by $34 \%$. In our study, three psychological needs reduced the direct effect between income and life satisfaction by $53 \%$, while income also had a direct effect on life satisfaction, which accounted for $47 \%$ of the variance. In other words about half of the explained variance of life satisfaction in our study was directly due to effect of income, and about half to income influencing psychological needs satisfaction which then influenced life satisfaction.

What stands out in this study is that we looked at the indirect effect of all three psychological needs simultaneously. Contrast analysis showed that the effects of needs on the relationship between income and life satisfaction were quite similar. The only difference found was between need for competence and need for relatedness, with need for competence having significantly higher indirect effect than need for relatedness. Giebel (2017) found in her qualitative analysis that autonomy had a prominent role among the basic psychological needs. In our quantitative analysis, the effect was only different between need for competence and need for relatedness. In other words, results indicated that higher relative income contributes to satisfaction of all three psychological needs, constructs that in turn contribute to higher life satisfaction. This is in line with findings that experiential purchases make people happier than material purchases (Van Boven \& Gilovich, 2003; Howell \& Hill, 2009). Recently, it has also been shown that psychological needs satisfaction fully mediated the relations between materialism and subjective well-being (Wang, Liu, Jiang \& Song, 2017).

Howell and Howell's (2008) meta-analysis has demonstrated that the relation between economic status and subjective well-being is the strongest within the low-income developing countries and the weakest within the high-income developing countries. Data from Croatia have not been included in that meta-analysis, but since Croatia is a high-income developing country, according to World Bank data, the relations we found might be even stronger in countries lower in economic development. Our sample also included mostly individuals with average and higher than average income, which means that people whose economic status within Croatia was lower, and whose basic needs were less likely to be satisfied, were not included in the analysis. Again, we might expect that the relations we observed would be even stronger if our sample included people with lower than average income. Howell and Howell (2008) showed that economic status-subjective well-being relationship was stronger when economic status was measured as wealth and not as income, which was the case in our study. Therefore, it would be interesting in some future studies to examine these relations using different measures of economic standing as well as different components of subjective well-being.

\section{Conclusion}

Results of this study contribute to better understanding of the relationship between income, satisfaction of psychological needs and life satisfaction. So would you be happier if you were rich(er)? Our results suggest that people who perceive they have more money compared to others: (i) are more satisfied with their lives, (ii) feel their psychological needs are more satisfied, and (iii) their need satisfaction further contributes to higher life satisfaction. 


\section{References}

Baard, P. P., Deci, E. L., \& Ryan, R. M. (2004). Intrinsic need satisfaction: A motivational basis of performance and well-being in two work settings. Journal of Applied Social Psychology, 34, 2045-2068.

Baron, R. M., \& Kenny, D. A. (1986). The moderator-mediator variable distinction in social psychological research: Conceptual, strategic and statistical considerations. Journal of Personality and Social Psychology, 51, 1173-1182.

Boyce, C. J., Brown, G. D. A., \& Moore, S. C. (2010). Money and happiness: Rank of income, not income, affects life satisfaction. Psychological Science, 21, 471-475.

Bratko, D., \& Sabol, J. (2006). Osobine ličnosti i osnovne psihološke potrebe kao prediktori zadovoljstva životom: rezultati on-line istraživanja [Personality and basic psychological needs as predictors of life satisfaction: results of the on-line study]. Društvena istraživanja, 15, 693-711.

Deci, E. L., \& Ryan, R. M. (1985). Intrinsic motivation and self-determination in human behavior. New York: Plenum.

Diener, E. (2006). Understanding scores on the satisfaction with life scale. Retrieved from http://internal.psychology.illinois.edu/ ediener/SWLS.html.

Diener, E., Ng, W., Harter, J. \& Arora, R. (2010). Wealth and happiness across the world: Material prosperity predicts life evaluation, whereas psychosocial prosperity predicts positive feeling. Journal of Personality and Social Psychology, 99, 52-61.

Diener, E., Tay, L., \& Oishi, S. (2013). Rising income and the subjective well-being of nations. Journal of Personality and Social Psychology, 104, 267-276.

Easterlin, R. (1974). Does economic growth improve the human lot? In: P. A. David, \& M. W. Reder (Eds.), Nations and Households in Economic Growth: Essays in Honor of Moses Abramovitz (pp. 89125), New York: Academic Press.

Gagné, M. (2003). The role of autonomy support and autonomy orientation in prosocial behavior engagement. Motivation and Emotion, 27, 199-223.

Giebel, C. (2017). "A Dream Come True"?: Interrelations between the basic psychological needs and flourishing in letters from a future with a basic income (Bachelor thesis, University of Twente, The Netherlands). Retrieved from http://essay.utwente.nl/72536/1/Giebel BA Faculty of Behavioural\%2C Management\%2 oand\%20Social Sciences.pdf

Hayes, A.F. (2013). An introduction to mediation, moderation, and conditional process analysis: $A$ regression-based approach. New York: Guilford Press.

Howell, R. T., \& Hill, G. (2009). The mediators of experiential purchases: Determining the impact of psychological needs satisfaction and social comparison. The Journal of Positive Psychology, 4, 511-522.

Howell, R. T., \& Howell, C. J. (2008). The relation of economic status to subjective well-being in developing countries: A meta-analysis. Psychological Bulletin, 134, 536-560.

Howell, R. T., Kurai, M., \& Tam, L. (2013). Money buys financial security and psychological need satisfaction: Testing need theory in affluence. Social Indicators Research, 110, 17-29.

Kahneman, D., \& Deaton, A. (2010). High income improves evaluation of life but not emotional well-being. PNAS, 107, 16489-16493.

Kaliterna Lipovčan, Lj., Brkljačić, T., \& Šakić, V. (2007). Monthly income and subjective well-being of Croatian citizens. Croatian Medical Journal, 48, 727-733. 
Karaoylas, E. C. (2010). Changes in well-being across the lifespan: A cross-sectional survey of young, middle-age, and older adults. Unpublished thesis. Manitoba: Department of psychology of University of Manitoba.

Pavot, W., \& Diener, E. (1993). Review of the satisfaction with life scale. Psychological Assessment, 5, 164172.

Pavot, W., \& Diener, E. (2008). The satisfaction with life scale and the emerging construct of life satisfaction. The Journal of Positive Psychology, 3, 137-152.

Raboteg-Šarić, Z., Brajša-Žganec, A., \& Šakić, M. (2009). Life satisfaction in adolescents: The effects of perceived family economic status, self-esteem and quality of family and peer relationships. Društvena istraživanja, 18, 547-564.

Ryan, R. M., \& Deci, E. L. (2000). Self-determination theory and the facilitation of intrinsic motivation, social development, and well-being. American Psychologist, 55, 68-78.

Ryff, C. D. (1989). Happiness is everything, or is it? Explorations on the meaning of psychological wellbeing. Journal of Personality and Social Psychology, 57, 1069-1081.

Tay, L. \& Diener, E. (2011). Needs and subjective well-being around the world. Journal of Personality and Social Psychology, 101, 354-365.

Van Boven, L., \& Gilovich, T. (2003). To do or to have? That is the question. Journal of Personality and Social Psychology, 85, 1193-1202.

Vansteenkiste, M., Ryan, R. M., \& Deci, E. L. (2008). Self-determination theory and the explanatory role of psychological needs in human well-being. In: L. Bruni, F. Comim \& M. Pugno (Eds.), Capabilities and happiness (pp. 187-223). Oxford, UK: Oxford University Press.

Véronneau, M.-H., Koestner, R. F., \& Abela, J. R. Z. (2005). Intrinsic need satisfaction and well-being in children and adolescents: An application of the self-determination theory. Journal of Social and Clinical Psychology, 24, 280-292.

Wang, R., Liu, H., Jiang, J., \& Song, Y. (2017). Will materialism lead to happiness? A longitudinal analysis of the mediating role of psychological needs satisfaction. Personality and Individual Differences, 105, 312-317. 
A. Butković et al. - Psychological Needs as Mediators of Income-Life ...

C O A $\mathbf{s}$ 